\title{
Physico-Chemical and Thermal
}

\section{Characterization of Some Lignocellulosic Fibres: Ananas comosus (AC), Neuropeltis acuminatas (NA) and Rhecktophyllum camerunense (RC)}

\author{
Achille Désiré Omgba Betene ${ }^{1,2 *}$, Fabien Ebanda Betene ${ }^{1,2}$, Florian Martoïa3, \\ Pierre J. J. Dumont ${ }^{3}$, Ateba Atangana ${ }^{1,2}$, Pierre Marcel Anicet Noah ${ }^{1,2}$ \\ ${ }^{1}$ Department of Mechanical Engineering, ENSET, University of Douala, Douala, Cameroon \\ ${ }^{2}$ Laboratory of Mechanics, University of Douala, Douala, Cameroon \\ ${ }^{3}$ University of Lyon, INSA-Lyon, CNRS UMR5259, LaMCoS, Lyon, France \\ Email: ^achilbetene@gmail.com
}

How to cite this paper: Betene, A.D.O., Betene, F.E., Martoïa, F., Dumont, P.J.J., Atangana, A. and Noah, P.M.A. (2020) Physico-Chemical and Thermal Characterization of Some Lignocellulosic Fibres: Ananas comosus (AC), Neuropeltis acuminatas (NA) and Rhecktophyllum camerunense (RC). Journal of Minerals and Materials Characterization and Engineering, 8, 205-222.

https://doi.org/10.4236/jmmce.2020.84014

Received: May 22, 2020

Accepted: July 5, 2020

Published: July 8, 2020

Copyright (อ 2020 by author(s) and Scientific Research Publishing Inc. This work is licensed under the Creative Commons Attribution International License (CC BY 4.0).

http://creativecommons.org/licenses/by/4.0/

\begin{abstract}
This paper focuses on the study of the physical, biochemical, structural, and thermal properties of plant fibres of Rhecktophyllum camerunense (RC), Neuropeltis acuminatas (NA) and Ananas comosus (AC) from the equatorial region of Cameroon. The traditional use of these fibres inspired researchers to investigated their properties. This study aims at improving the state of knowledge with a view to diversifying applications. The fibres are extracted by retting. Then, their apparent density was measured following the ASTM D792 standard and their water moisture absorption and moisture content were also evaluated. Their molecular structure was studied by ATR-FTIR spectroscopy. A quantitative analysis of the biochemical composition was performed according to the analytical technique for the pulp and paper industry (TAPPI). A TGA/DSC analysis was also performed. The results reveal that the AC, NA and RC fibres have densities of $1.26 \pm 1.06,0.846 \pm 0.13$ and $0.757 \pm 0.08 \mathrm{~g} \cdot \mathrm{cm}^{-3}$ respectively. They are also hydrophilic with a water absorption rate of $188.64 \pm 11.94 \%, 276.16 \% \pm 8.07 \%$ and $198.17 \% \pm 20 \%$. They have a moisture content of $12.21 \%, 10.36 \%$ and $9.37 \%$. The studied fibres exhibit functional groups that are related to the presence of hemicellulose, pectin, lignin and cellulose. The cellulose crystallinity index was found to be $67.99 \%, 46.5 \%$ and $59.72 \%$ respectively. The fibres under study have the following chemical composition: an extractive content of $3.07 \%, 14.77 \%$ and 8.74\%; a pectin content of $4.15 \%, 7.69 \%$ and $3.45 \%$; a hemicellulose content of $4.90 \%, 15.33 \%$ and $7.42 \%$; a cellulose content of $68.11 \%, 36.08 \%$ and
\end{abstract}


$65.15 \%$; a lignin content of $12.01 \%, 25.15 \%$ and $16.2 \%$; and an ash content of $0.27 \%, 1.53 \%$ and $0.47 \%$ respectively. The thermal transitions observed on the thermograms correlate with the TAPPI chemical composition. It is observed that these fibres are thermally stable up to temperatures of $200^{\circ} \mathrm{C}, 220^{\circ} \mathrm{C}$ and $285^{\circ} \mathrm{C}$. These results make it possible to envisage uses similar to those of sisal, hemp and flax fibres.

\section{Keywords}

Lignocellulosic Fibre, Rhecktophyllum camerunense, Neuropeltis

acuminatas, Ananas comosus, Biochemical Composition, Cellulose

Crystallinity Index, Thermal Behaviour

\section{Introduction}

The use of plant fibres (cotton, flax, jute, coconut, wood fibres, etc.) as biobased fibrous reinforcements for polymer and ceramic materials is a current industrial option in the perspective of promoting the development of renewable resources. These fibres are used to obtain insulation panels or are added to polymer or plaster matrices for the design of composites. Many studies aim at identifying fibres with properties that are favourable for industrial applications. It is therefore necessary to evaluate their density, porosity, chemical composition, structural characteristics (slenderness, cross-section shape and area, microfibril angle), mechanical strength, thermal stability and sensitivity to the absorption of moist liquids and vapours [1] [2] [3]. In this perspective of finding new fibrous plant resources, research can draw inspiration from the traditional uses of the ecosystem resources of our immediate environment: ropes, pots, fishing nets, toilet gloves, handicraft furniture and mats. Through these uses, these materials seem to resist severe mechanical and thermophysical stresses. This inspired researchers to investigate the properties of AC, NA and RC fibres. Their work has identified some of their physical, chemical, hygroscopic and mechanical characteristics.

A study on the RC fibre (elementary fibres or in the form of bundles) [1] revealed a density of $0.947 \mathrm{~g} \cdot \mathrm{cm}^{-3}$, a cellulose content of $68.5 \%$, a microfibril angle of $40.11^{\circ}$, a tensile Young's modulus ranging between 2.3 and $17 \mathrm{GPa}$, an elongation ranging between $10.9 \%$ to $53 \%$ and a tensile strength comprised between 150 and $1738 \mathrm{MPa}$. When used as reinforcement in plaster [4], these fibres improve the mechanical, thermal and hygroscopic properties of these materials. They confer to plaster a more ductile fracture behaviour and reduce the kinetics of heat propagation. RC plasters are also more moisture absorbent than unreinforced plaster, which qualifies them for comfort and building application applications.

Previous studies [5] [6] that the NA fibres (elementary fibres or in the form of bundles) have a rectangular cross-section, Young's modulus of $6 \mathrm{GPa}$, tensile stress of $62 \mathrm{MPa}$ and an elongation at break of $0.01 \%$, cellulose crystallinity in- 
dex of $42 \%$. Their microfibril angle is $1.4^{\circ}$, their cellulose content $39.2 \%$ and their lignin content $20.4 \%$. The latter is high compared to fibres such as flax, bamboo, kenaf and sisal.

AC fibre has generally been used in the manufacture of yarns for textile fabrics for several decades [7]. AC fibre has been used in the for example in the Pinatex fabric is an alternative to leather in the production of sporting goods and bags. It is reported [7] that AC fibres extracted from Malaysian pineapple leaf species are one of the natural fibres with the highest cellulose content $(80 \%)$ compared to kenaf (57\%), flax (71\%), jute (71.5\%), sisal (78\%), hemp (77\%). Moreover, its density of $1.6 \mathrm{~g} \cdot \mathrm{cm}^{-3}$ is similar to other natural fibres e.g., cotton, jute, flax, hemp, sisal, ramie. While it's Young's modulus ( $83 \mathrm{GPa}$ ) is higher or of the same order of magnitude as that of than that of cotton (12.6 GPa), jute (80 $\mathrm{GPa})$, flax (70 GPa), sisal (6 GPa), and its tensile strength (1627 MPa) is the highest compared to cotton (597 MPa), jute (800 MPa), flax (1500 MPa).

Plaster setting [4] and cross-linking of thermosetting matrices [8] can lead to temperature rises that can degrade the lignocellulosic the fibres. As far as we know, no studies on AC, NA and RC fibres have been carried out to characterize their thermal properties such as thermal stability and thermal transitions. However, it is important to consider these properties to select application for composite materials that will not degrade these reinforcement fibres. This work is intended to complete the knowledge of these fibres by studying their thermal behaviour. For validation or comparison purposes, the evaluation of their properties has also been performed.

\section{Experimental}

\subsection{Fibres Extraction}

Figures 1-3 show the main steps in the extraction of harvested plant material and the fibres extracted.

\subsubsection{AC Fibres}

Pineapple leaves were harvested from adult plants in a field in the locality of

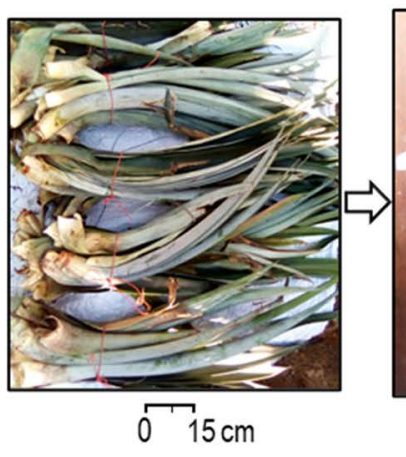

Pineapple plants leaves

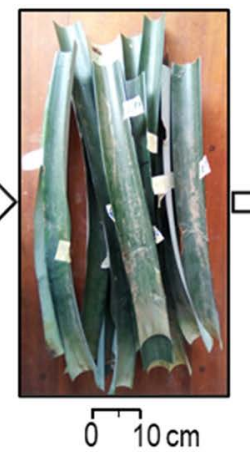

Cut pineapple leaves

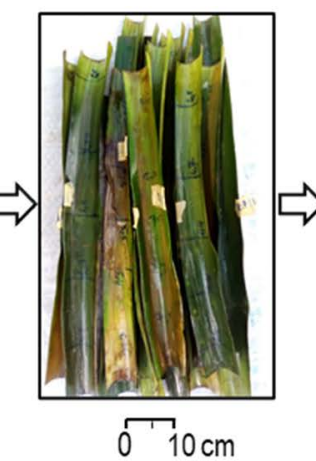

Russet pineapple leaves

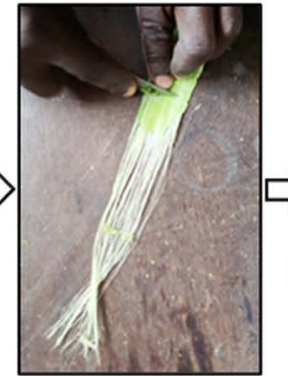

$510 \mathrm{~cm}$

Scraping the pineapple leaves

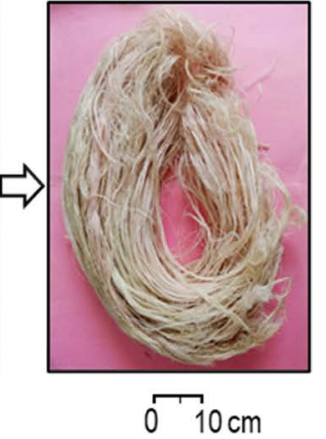

AC fibres

Figure 1. Image showing the main steps of the AC fibre extraction process. 


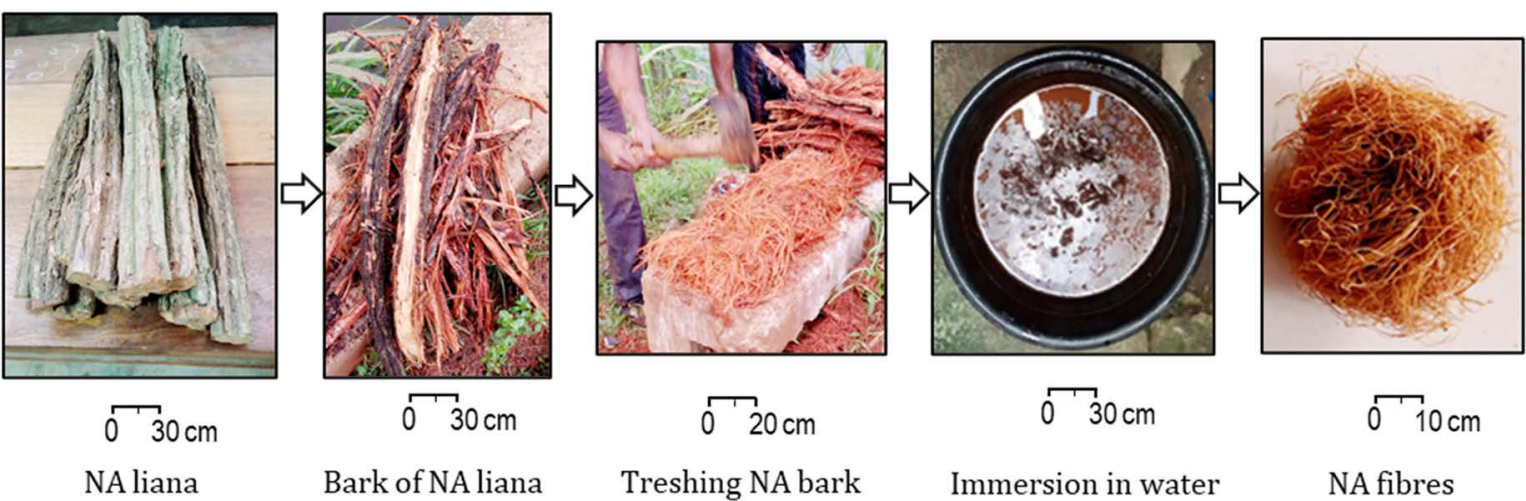

Figure 2. Image showing the main steps of the NA fibre extraction process.

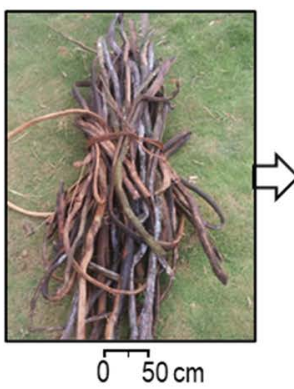

Aerial roots of the RC plant

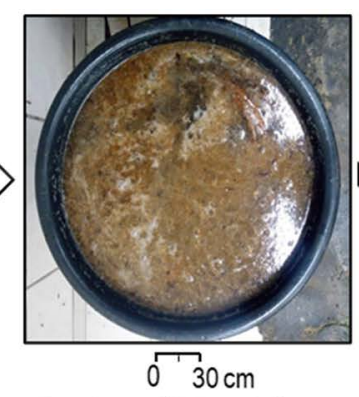

Retting of $\mathrm{RC}$ aerial roots

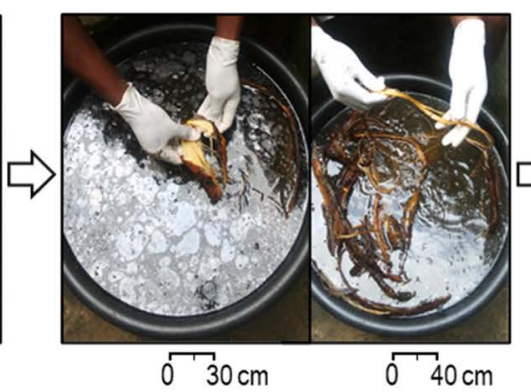

Shelling the fibres of root of RC

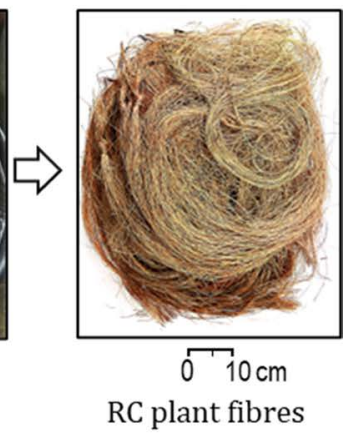

$\mathrm{RC}$ plant fibres

Figure 3. Image showing the main steps RC fibre extraction process.

Njombé-Penja on the Cameroonian coast. The average temperature of this locality is $31^{\circ} \mathrm{C}$, with a relative humidity of $73 \%$. The harvested leaves were cut off at their ends and then immersed in stagnant water from the national distribution network for four days. When the leaves reddened, they were subjected to a kind of decortication that left only the fibres remaining. The fibres were rinsed with distilled water and then dried in the shade for 24 hours.

\subsubsection{NA Fibres}

NA lianas were harvested in the equatorial forest of Mvila-Yëvol in South Cameroon. The bark was peeled off on pieces previously cut into $50 \mathrm{~cm}$ long pieces, then they were beaten with a $2 \mathrm{~kg}$ sledgehammer. The fibres were extracted by retting with stagnant water from the national distribution network.

\subsubsection{RC Fibres}

The aerial roots of RC were harvested in the undergrowth of the Nkol-Mefembe equatorial forest in Central Cameroon. They were cut into $100 \mathrm{~cm}$ long pieces and then laminated. The laminated roots were immersed in water from the national distribution network. After 4 days of immersion, the fibres were extracted, rinsed and dried at room temperature away from the sun for 24 hours.

\subsection{Physical Properties}

The individual weighing operations were carried out using a $0.1 \mathrm{mg}$ precision bal- 
ance. Each test was carried out on 10 samples and the reported result is the average.

\subsubsection{Apparent Density}

The apparent density $\rho_{f}$ of AC, NA and RC fibres was calculated by dividing the mass by the volume as shown in Equation (1) based on ASTM D3800-99 (2005) and ASTM D792 (2013). These standards allow the bulk density to be evaluated by the gravimetric method based on Archimedes principle. First, the mass of the fibres $m_{f}$ previously dried at $50^{\circ} \mathrm{C}$ for 24 hours was measured. The samples are made up by covering these fibres with paraffin of volume $v_{p}$. The volume of the sample $v_{t}$ was evaluated by immersion in a test tube containing a volume of distilled water $v_{0}\left(\right.$ at $\left.25^{\circ} \mathrm{C}\right)$. A metallic volume element $v_{a}$ ensures the immersion of the sample. The volume $v_{f}$ of the fibres was determined by Equation (2).

$$
\begin{gathered}
\rho_{f}=\frac{m_{f}}{v_{f}} \\
v_{f}=v_{t}-\left(v_{p}+v_{a}+v_{0}\right)
\end{gathered}
$$

\subsubsection{Water Absorption Rate (\%TA)}

The water absorption rate of the studied fibres previously dried at $105^{\circ} \mathrm{C}$ for 24 hours was evaluated using Equation (3) [9]. Ten samples with a mass $m_{0}$ were prepared. These samples were immersed in distilled water for 24 hours at room temperature. The mass $m_{1}$ after absorption was measured after cleaning the water from the surface of the samples.

$$
\% T A=\frac{m_{1}-m_{0}}{m_{0}} \times 100
$$

\subsubsection{Moisture Content $\left(\% H_{u}\right)$}

The moisture content of plant fibres was determined using Equation (4) [9] [10]. Ten samples with the mass $m_{i}$ were placed at room temperature $25^{\circ} \mathrm{C} \pm 2{ }^{\circ} \mathrm{C}$ with $63 \%$ relative humidity for 24 hours. The hydrophilic character favours the absorption of relative humidity from the air of the plant fibres [10]. Finally, the samples were dehumidified in an oven set at $105^{\circ} \mathrm{C}$ for 24 hours and the final mass $m_{f}$ of each sample was measured.

$$
\% H_{u}=\frac{m_{i}-m_{f}}{m_{i}} \times 100
$$

\subsection{Chemical Composition of Fibres}

Quantitative analyses of fibre constituents were carried out using the TAPPI method on dry powdered fibres with a mean particle size of approximately 315 $\mu \mathrm{m}$. Weighings were carried out on a $0.1 \mathrm{mg}$ precision balance.

\subsubsection{Ethanol-Benzene Extraction (\%Es)}

A cartridge containing an average of $6 \mathrm{~g}$ of powdered fibres was introduced into 
a Soxhlet. The latter is mounted between a flask charged with ethanol (96\%) benzene $(99 \%) ; d=0.878)(1: 2 \mathrm{v} / \mathrm{v})$ solvent and a refrigerator. This assembly is fixed on a bracket. The separation of the extractives was made by regulated leaching so as to have a siphon every 10 minutes. Dissolution was done for 7 hours. The cartridges were removed from the Soxhlet, freeze-dried at $50^{\circ} \mathrm{C}$ for 1 hour then cooled in a desiccator. The level of ethanol-benzene extractives ( $\% E s)$ was determined using Equation (5) [11] [12].

$$
\% E s=\frac{m_{E s}}{m_{d}} \times 100
$$

where $m_{E s}$ is the mass of the ethanol-benzene extractives and $m_{d}$ the mass of previously dried fibre removed.

\subsubsection{Water Extraction ( $\% W s$ )}

The dried cartridges (residue 1) of ethanol-benzene were introduced into the Soxhlet. The previous assembly was reconstituted by replacing the solvent with $100 \mathrm{ml}$ of distilled water. The mixture was heated under reflux for 7 hours. The Residue 2 obtained was filtered on a weighed sintered glass crucible No 4, washed with distilled water, incubated at $105^{\circ} \mathrm{C}$ for 12 hours, then weighed after cooling in a desiccator. The content of hot water extractives ( $\% W s)$ was determined by Equation (6) [11] [12].

$$
\% W s=100 \times \frac{m_{W}}{m_{r e s 1}}(1-\% E s)
$$

with $m_{W}$ the mass of the water extractables, $m_{\text {res } 1}$ is the dry mass of residue 1.

The extractive content $\left(\% E_{X}\right)$ of the fibres is the sum of the hot water and ethanol-benzene extractives.

\subsubsection{Pectin Content $(\% P s)$}

$1.5 \mathrm{~g}$ of residue 2 was introduced into an Erlenmeyer flask containing a $2 \%$ hydrochloric acid solution. The mixture was heated under reflux with magnetic stirring in a water bath at $80^{\circ} \mathrm{C}$ for 4 hours. Residue 3 was retained by filtration on a weighed sintered glass crucible No 4 , washed with distilled water, dried at $105^{\circ} \mathrm{C}$ for 12 hours and weighed after cooling in a desiccator. The pectin content $(\% P S)$ in the hydrochloric acid extract was determined by Equation (7) [11] [12].

$$
\% P s=100 \times \frac{m_{P S}}{m_{\text {res } 2}}(1-\% E x)
$$

where $m_{P s}$ is the mass of pectin extracted, $m_{\text {res } 2}$ is the dry mass of residue 2.

\subsubsection{Lignin Content ( $\% L$ )}

The lignin content was carried out according to the Klason method. $500 \mathrm{mg}$ of the dried residue 2 was hydrolysed in $72 \%$ sulphuric acid. Lignin being the only insoluble component, it separates from the fibres. Then, the lignin content was determined using Equation (8) [11] [12]. 


$$
\% L=100 \times \frac{m_{L}}{m_{\text {res } 2}}(1-\% E x)
$$

where $m_{L}$ is the mass of lignin extracted.

\subsubsection{Holocellulose Content $(\% H C)$}

$1.5 \mathrm{mg}$ of residue 2 was placed in a flask containing $60 \mathrm{ml}$ of distilled water heated to $75^{\circ} \mathrm{C}$. Subsequently, $0.2 \mathrm{ml}$ acetic acid and $15 \% \mathrm{v} / \mathrm{v}(3 \mathrm{ml}$ ) sodium chlorite were added every hour for seven hours. The residue 4 obtained was filtered and then washed with demineralised water and left to stand for two hours before being washed again with ethanol. This residue was dried at $105^{\circ} \mathrm{C}$ [11]. The holocellulose content was determined using Equation (9) [11] [12].

$$
\% H C=100 \times \frac{m_{H C}}{m_{\text {res } 2}}(1-\% E x)
$$

where $m_{H C}$ is the mass of holocellulose extracted.

\subsubsection{Cellulose Content $(\% C)$}

Cellulose was isolated according to the method of Kurschner and Hoffer [1] [11]. $1 \mathrm{~g}$ of holocellulose was introduced into an Erlenmeyer flask containing 50 $\mathrm{ml}$ of solvent nitric acid-ethanol (1:4; v/v) prepared from ethanol (96\%) and nitric acid $(16 \mathrm{~N})$. The assembly was connected to a refrigerant and then heated in a water bath for 1 hour. The solution obtained was filtered using a weighed sintered crucible No. 4, washed with ethanol, then with demineralised water and finally with ether. The cellulose obtained was freeze-dried at $105^{\circ} \mathrm{C}$ for 12 hours, cooled for 12 hours in a desiccator and weighed. The cellulose content $(\% C)$ was determined by Equation (10) [11] [12].

$$
\% C=100 \times \frac{m_{C}}{m_{H C}}(1-\% H C)
$$

where $m_{C}$ is the mass of cellulose obtained, $m_{H C}$ is the mass of holocellulose removed.

\subsubsection{Hemicellulose Content $(\% H)$}

Holocellulose consists mainly of cellulose and hemicellulose [11] [12]. The hemicellulose content was determined using Equation (11).

$$
\% H=\% H C-\% C
$$

\subsubsection{Ash Content ( $\% C s)$}

The ground fibres were placed in a porcelain crucible and then calcined at $600^{\circ} \mathrm{C}$ in a kiln for 6 hours. The ash content was estimated using Equation [11] [12].

$$
\% C s=\frac{m_{C s}}{m_{d}} \times 100
$$

where $m_{C s}$ is the mass of the ashes and $m_{d}$ is the mass of the sample taken.

\subsection{ATR-FTIR Analysis}

The main purpose of this analysis was to identify the functional groups of the 
studied fibres. The spectra are recorded using a Bruker Alpha-P spectrometer, equipped with an attenuated total reflectance (ATR) module with a diamond crystal and driven by the Opus/Mentor software. The plant fibres were dried at $50^{\circ} \mathrm{C}$ for 24 hours and then powdered to the size of $315 \mu \mathrm{m}$. A few milligrams of powder from the plant fibres studied were deposited on the diamond crystal of the ATR module. Acquisitions were carried out by scanning over a spectral region ranging from 4000 to $400 \mathrm{~cm}^{-1}$ with a resolution of $4 \mathrm{~cm}^{-1}$.

The crystallinity of cellulose $\chi$ in AC, NA and RC fibres was determined by comparing the peak intensities of the FTIR spectra at $1454 \mathrm{~cm}^{-1}$ and $893 \mathrm{~cm}^{-1}$ [13] as shown in Equation (13):

$$
\chi=\frac{I_{1454}}{I_{893}}
$$

where $I_{1454}$ and $I_{893}$ are the intensities of the FTIR peaks at $1454 \mathrm{~cm}^{-1}$ and $893 \mathrm{~cm}^{-1}$ respectively.

\subsection{TGA-DSC Analysis}

Thermal analysis was performed on a synchronous STA PT-1000 Linseis thermogravimetric analyzer with $0.5 \mu \mathrm{g}$ resolution capable of combining TG (Thermogravimetric) and DSC (Differential Scanning Calorimetry) information using the same sample. The device was equipped with a high-resolution $0.1 \mathrm{mg}$ loaded balance, a furnace with a maximum calcination temperature of $1000^{\circ} \mathrm{C}$ and a very fast cooling system. The device was connected to a computer and controlled by the Platinum Evaluation v1.0.182 software.

3 to $5 \mathrm{mg}$ of powdered fibres $(\sim 315 \mu \mathrm{m})$ were introduced into a platinum crucible and then heated in the furnace at a constant heating rate of $10^{\circ} \mathrm{C} / \mathrm{min}$ in a temperature range from $25^{\circ} \mathrm{C}$ to $700^{\circ} \mathrm{C}$ under nitrogen flow at a rate of $50 \mathrm{ml} / \mathrm{min}$.

\section{Results}

\subsection{Physical Properties}

Several physical property values for fibres in the studies and for some fibres in the literature are given in Table 1.

\subsubsection{Density of Fibres}

The fibre densities (Table 1) found for AC, NA et RC fibres are close to those reported in the literature for the same species [1] [4] [14] [15]. The use of AC, NA and RC fibres could significantly contribute to lighten the mass of composites used in the fields of transport, construction, sport and leisure.

\subsubsection{Water Absorption Rate of the Fibres}

The values of the water absorption rate (Table 1) are under study are high (above 100\%). These fibres are hydrophilic similarly as sisal, flax, jute and roselle. This hydrophilic character of plant fibres is generally attributed to the presence of hemicelluloses due to their many ramifications [2] [3]. This capacity to absorb water most often leads to a decrease in the mechanical strength of the 
Table 1. Density and water absorption rate of AC, NA and RC plant fibres.

\begin{tabular}{ccccc}
\hline Fibre & Density $\left(\mathbf{g} \cdot \mathrm{cm}^{-3}\right)$ & $\begin{array}{c}\text { Water absorption } \\
\text { rate (\%) }\end{array}$ & $\begin{array}{c}\text { Moisture } \\
\text { content (\%) }\end{array}$ & References \\
\hline Sisal & 1.5 & $190-250$ & $5-10$ & {$[7][14]$} \\
Hemp & $1.15-1.45$ & - & $6.2-12$ & {$[7][16]$} \\
RC & $0.63-0.947$ & - & 7.5 & {$[1][4][17]$} \\
NA & 0.918 & 400 & - & {$[14]$} \\
AC & 1.526 & - & 12 & {$[7][15]$} \\
Jute & $1.3-1.41$ & 281 & $12-13.7$ & {$[2][3][7][18]$} \\
Flax & 1.5 & $136 \pm 25$ & 12 & {$[2][3][19]$} \\
Cotton & $1.5-1.6$ & - & $8-25$ & {$[7][16]$} \\
Roselle & 1.41 & 286.5 & 10.9 & {$[9]$} \\
Kenaf & 1.45 & - & - & [17] \\
AC & $\mathbf{1 . 2 5 6 \pm 0 . 0 6}$ & $\mathbf{1 8 8 . 6 4} \pm 12$ & 12.21 & - \\
NA & $\mathbf{0 . 8 4 3} \pm \mathbf{0 . 1 3}$ & $\mathbf{2 7 6 . 1 6 \pm 8 . 0 7}$ & 10.36 & - \\
RC & $\mathbf{0 . 7 5 7} \pm \mathbf{0 . 0 8}$ & $\mathbf{1 9 8 . 1 7} \pm \mathbf{2 0 . 2 3}$ & $\mathbf{9 . 3 7}$ & \\
\hline
\end{tabular}

fibre, as well as a decrease in stiffness and the appearance of cracks in the composite [3] [7]. This characteristic could be improved by surface treatments and coupling agents [8] [10] [20].

\subsubsection{Moisture Content}

The initial moisture content of the fibres studied are reported in Table 1. It is noted that the moisture content of AC fibres is higher than those of NA and RC. This can be attributed to the relative humidity of the harvesting site, i.e. $73 \%$ for AC, $61 \%$ for RC and $65 \%$ for NA. This sensitivity to wet vapours is also attributed to the presence of free hydroxyl groups [7] [15].

\subsection{Chemical Composition}

The results of the biochemical analysis of the fibres studied and other plant fibres are presented in Table 2 . The studied fibres content cellulose $(\% C)$, hemicellulose $(\% H)$, lignin $(\% L)$, pectins $(\% P s)$, extractives $(\% E x)$ and ash $(\% C s)$. This corresponds to the description of the chemical composition of plant fibres in the literature [1] [5] [11] [12].

The extractive content is higher for NA (12.77\%) than for RC (8.74\%) and AC (3.07\%). The content of NA extractives is close to the value reported in a recent study [5]. According to the literature [11] [21], if the content of hot water extractives is less than $7 \%$, there is good compatibility with inorganic binders. Hence, the values obtained for $\mathrm{AC}$ and $\mathrm{RC}$ fibres show that these lignocellulosic fibres can be considered as fairly compatible with gypsum, cement, earth, clay. NA fibres contain almost twice as many pectins as AC and NA fibres. These contents are very close to that of banana fibres [12]. The difference between the 
Table 2. Chemical composition by the TAPPI method of plant fibres of AC, NA and RC.

\begin{tabular}{|c|c|c|c|c|c|c|c|c|}
\hline \multirow{3}{*}{ Fibre } & \multicolumn{8}{|c|}{ Chemical composition (\%) } \\
\hline & \multicolumn{2}{|c|}{$\% H C$} & \multirow{2}{*}{$\% L$} & \multirow{2}{*}{$\% P s$} & \multicolumn{2}{|c|}{$\% E x$} & \multirow{2}{*}{$\% C s$} & \multirow{2}{*}{ Ref. } \\
\hline & $\% C$ & $\% H$ & & & $\% E_{E B}$ & $\% W_{s}$ & & \\
\hline Banana & 37.5 & 27.6 & 15 & 5.15 & 0.2 & 12 & - & {$[12]$} \\
\hline $\begin{array}{c}\text { Eucalyptus } \\
\text { saligna }\end{array}$ & 48.6 & 12.4 & 38.4 & - & 2.4 & 2.6 & 0.092 & {$[11]$} \\
\hline $\begin{array}{l}\text { Cupressus } \\
\text { lusitanica }\end{array}$ & 48.4 & 21.6 & 34.3 & - & 3.4 & 3.2 & 0.57 & [11] \\
\hline NA & 39.24 & 7.22 & 20.47 & 2.07 & \multicolumn{2}{|c|}{18.90} & 2.18 & {$[5]$} \\
\hline $\mathrm{RC}$ & 68.2 & - & 15.6 & - & \multicolumn{2}{|c|}{-} & - & {$[1]$} \\
\hline $\mathrm{AC}$ & $67.12-82$ & $9.45-18.8$ & $4.4-15.4$ & $1.2-3$ & \multicolumn{2}{|c|}{-} & $0.9-2.7$ & {$[15]$} \\
\hline Jute & $61-75$ & $13.6-20.4$ & $12-13$ & 0.2 & \multicolumn{2}{|c|}{-} & - & [1] \\
\hline Lin & 64.1 & 16.7 & 2 & 1.8 & \multicolumn{2}{|c|}{3.9} & - & [1] [2] \\
\hline Sisal & 65.8 & 12 & 9.9 & 0.8 & \multicolumn{2}{|c|}{1.2} & - & [1] [2] \\
\hline $\mathrm{AC}$ & 68.11 & 4.90 & 12.01 & 4.15 & 0.99 & 2.08 & 0.27 & - \\
\hline NA & 36.08 & 15.33 & 25.15 & 7.69 & 3.20 & 9.57 & 1.53 & - \\
\hline RC & 65.15 & 7.42 & 16.2 & 3.45 & 2.17 & 3.05 & 0.42 & - \\
\hline
\end{tabular}

values found in this study and those reported in the literature [5] [15] can be attributed to the method used. The lignin content of AC fibres is lower than that of NA and RC fibres. However, these values are close to those reported in the literature [1] [5] [7]. It is also observed that the lignin content of AC and RC fibres is similar to that of jute and banana fibres [1] [12], while the lignin content of NA fibres is similar to that of wood fibres of Eucalyptus species [11]. The lignin content of NA fibres could be recovered and valorized in the production of biofuels. The hemicellulose contents of the fibres investigated in this study are close to those in the literature. For NA fibres the higher hemicellulose content obtained correlates with its water absorption rate and confirms its more hydrophilic character compared to AC and RC fibres. The values obtained show that cellulose is the predominant constituent for all fibres studied, which is consistent with the literature [1]. It can be seen that the cellulose content of RC (65.15\%) and AC (68.11\%) fibres is almost the same. These values are close to those obtained in previous studies on the same species. It is also noted that these values are similar to other industrial plant fibres such as jute (61\% - 75\%), flax (64.1\%) and sisal (65.8\%). According to previous studies [1], the cellulose content of plant fibres commonly used in composites has a cellulose content of $50 \%-85 \%$. Based on these results, AC and RC fibres can be considered as fairly compatible with gypsum, for instance. The cellulose content of NA fibres $(36.08 \%)$ is the lowest among the fibres studied, but remains close to that reported in a recent study [5] and to banana fibres [12]. The low ash content obtained for all types of fibres is in accordance with the data available in the literature. 
The amounts of the chemical constituents of AC, NA and RC fibres here are similar to those obtained in previous studies. In addition, cellulose, lignin and hemicelluloses represent at least $75 \%$ of the dry mass of the fibres studied. Hence, these fibres constitute promising biobased fibrous reinforcements for composite materials. Owing to their chemical composition close to that of many other types of natural fibres already used in composite applications such as flax and jute fibres, $\mathrm{RC}$ and $\mathrm{AC}$ fibres are expected to provide a better reinforcing effect compared with NA fibres.

\subsection{Molecular Structure of Fibres}

The spectra from the ATR-FTIR analyses are shown in Figure 4. The parameters of their identification are gathered in Table 3. These spectra are similar and

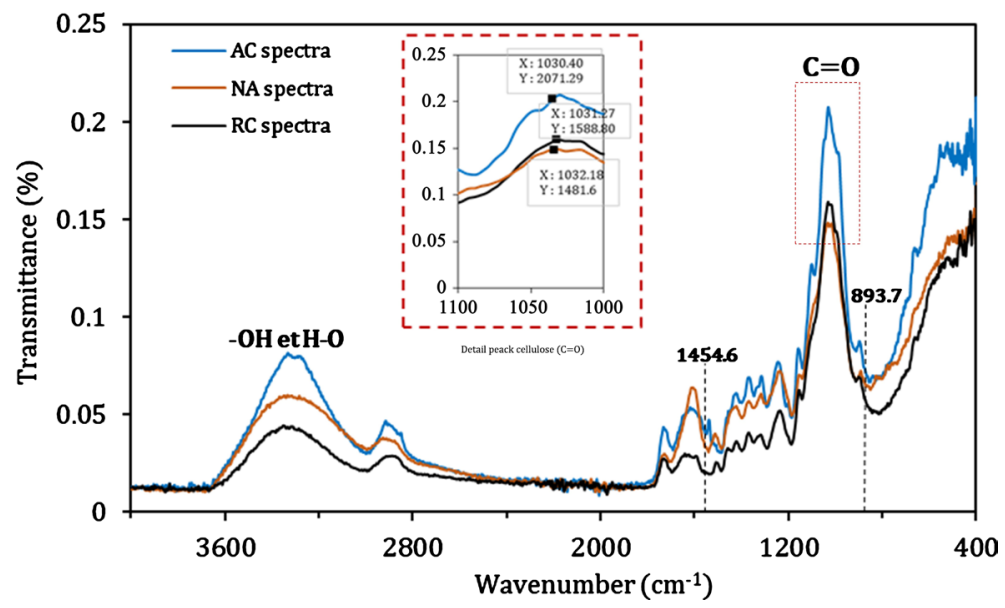

Figure 4. ATR-FTIR spectra of AC, NA and RC fibres.

Table 3. Absorption bands of the functional groups characteristic of AC, NA and RC fibres.

\begin{tabular}{|c|c|c|c|c|}
\hline \multicolumn{3}{|c|}{ Wavenumber $\left(\mathrm{cm}^{-1}\right)$} & \multirow{2}{*}{ Assignments } & \multirow{2}{*}{ References } \\
\hline $\mathrm{AC}$ & NA & RC & & \\
\hline 3333.52 & 3335.12 & 3332.40 & $\begin{array}{l}\text { Elongation of }-\mathrm{OH} \text { from hemicelluloses and } \mathrm{O}-\mathrm{H} \\
\text { from cellulose }\end{array}$ & {$[24][28][30]$} \\
\hline 2916.83 & 2929.15 & 2996.52 & Stretching of C-H and $\mathrm{CH}_{2}$ of cellulose & {$[13][22][23]$} \\
\hline 1733.03 & 1729.24 & 1730.67 & $\begin{array}{l}\text { Symmetric } \mathrm{C}=\mathrm{O} \text { prolongation of hemicelluloses } \\
\text { and pectins }\end{array}$ & [12] [22] [27] [31] \\
\hline 1632.25 & 1631.21 & 1634.50 & Shearing of the $-\mathrm{OH}$ bond in open water & {$[22][23]$} \\
\hline 1539.25 & 1508.46 & 1512.81 & Symmetrical stretching of $\mathrm{C}=\mathrm{C}$ of lignin & {$[24][31]$} \\
\hline 1454.62 & 1454.62 & 1454.62 & $\begin{array}{l}\text { Bending of } \mathrm{CH}_{2} \text { in cellulose and asymmetric } \\
\text { deformation of } \mathrm{CH}_{3} \text { in cellulose. }\end{array}$ & {$[13]$} \\
\hline 1030.40 & 1032.18 & 1031.27 & $\begin{array}{l}\text { Elongation vibration of the }-\mathrm{OH} \text { and } \mathrm{C}=\mathrm{O} \text { bonds } \\
\text { of cellulose. }\end{array}$ & {$[24][28]$} \\
\hline 893.74 & 893.74 & 893.74 & $\begin{array}{l}\text { Symmetrical stretching of the } \mathrm{C}-\mathrm{H} \text { and } \mathrm{O}-\mathrm{H} \\
\text { bonds of cellulose. }\end{array}$ & [13] \\
\hline
\end{tabular}


show absorption bands similar to lignocellulosic fibres such as hemp and flax [22], alfa [23] [24], rush [24], banana [12] [25]. The IR spectra show many peaks, which are commonly observed in plant fibres [12] [22] [24] [26]. The strongest peak located at $1030.40 \mathrm{~cm}^{-1}$ (AC), 1032.18 (NA) and 1031.27 (RC) corresponds to the stretching of $-\mathrm{OH}$ and $\mathrm{C}=\mathrm{O}$ bonds present in cellulose.

The polymeric $-\mathrm{OH}$ groups of hemicelluloses and the hydrogen bonds $(\mathrm{O}-\mathrm{H})$ of the supramolecular structure of cellulose present in the fibres under study are strongly reflected in the band at about $3333.32,3352.4$ and $3335.12 \mathrm{~cm}^{-1}$ for AC, NA and RC, respectively. The characteristic peaks at 2916.83, 2929.15 and $2896.56 \mathrm{~cm}^{-1}$ for AC, NA and RC, respectively, show the stretching of aliphatic and aromatic $\left(\mathrm{C}-\mathrm{H}, \mathrm{CH}_{2}\right)$ groups present in cellulose [13] and lignin [25]. The peaks 1733.03 for $\mathrm{AC}, 1729.24$ for NA and $1730.67 \mathrm{~cm}^{-1}$ for RC represent the symmetrical elongation of carboxyl and acetyl $(\mathrm{C}=\mathrm{O})$ groups present in hemicelluloses [29], pectin and waxes [22]. The peaks at 1539.25 (AC), 1508.46 (NA) and $1512.81 \mathrm{~cm}^{-1}(\mathrm{RC})$ indicate the symmetrical elongation of aromatic groups $(\mathrm{C}=\mathrm{C})$ in lignin. The small peak at $1454.63 \mathrm{~cm}^{-1}$ indicates not only the asymmetrical deformation of $\mathrm{CH}_{3}$ in cellulose [13], but also the bending of $\mathrm{CH}_{2}$ [28] [29]. The mode at $893.73 \mathrm{~cm}^{-1}$ fibres indicates the symmetrical stretching of the $\mathrm{C}-\mathrm{H}$ and $\mathrm{O}-\mathrm{H}$ bonds in cellulose and lignin [13].

Figure 4 is also used to estimate the crystallinity index of cellulose in plant fibres. The transmittance of peaks at 1454 and $893 \mathrm{~cm}^{-1}$ is $0.04908 \%$ and $0.07219 \%$ for AC, $0.03203 \%$ and $0.06888 \%$ for NA, and $0.0515 \%$ and $0.08624 \%$ for RC, respectively. The values obtained are presented in Table 4 . The crystallinity in cellulose of AC (67.99\%) is higher than that of the other two fibres and is similar to that of Luffa cylindrica cellulose (74.71\%) [13]. This value of cellulose crystallinity rate could be related to predict high fibre stiffness with high specific Young's modulus compared to RC and NA fibres.

\subsection{Thermal Properties}

\subsubsection{Thermal Characteristics DSC}

Figure 5 shows the DSC thermograms of fibre particles $(115 \mu \mathrm{m})$ of AC, NA and RC.

The DSC curves of the three fibres are similar and show one exothermic and three endothermic peaks. The first convex endothermic peak in each thermogram is attributed to water loss in the fibres [32]. It is observed at $69^{\circ} \mathrm{C}$ for AC fibres, $72^{\circ} \mathrm{C}$ for NA fibres and $79^{\circ} \mathrm{C}$ for RC fibres. This thermal event shows that drying of the fibres prior to analysis did not completely remove water. The three concave exothermic peaks probably correspond to the degradation of hemicelluloses, the

Table 4. Cellulose crystallinity index of AC, NA and RC fibres estimated by FTIR.

\begin{tabular}{cccc}
\hline \multicolumn{4}{c}{ Degree of crystallinity (\%) } \\
\hline Fibre & AC & NA & RC \\
\hline$\chi$ & 67.99 & 46.5 & 59.72 \\
\hline
\end{tabular}




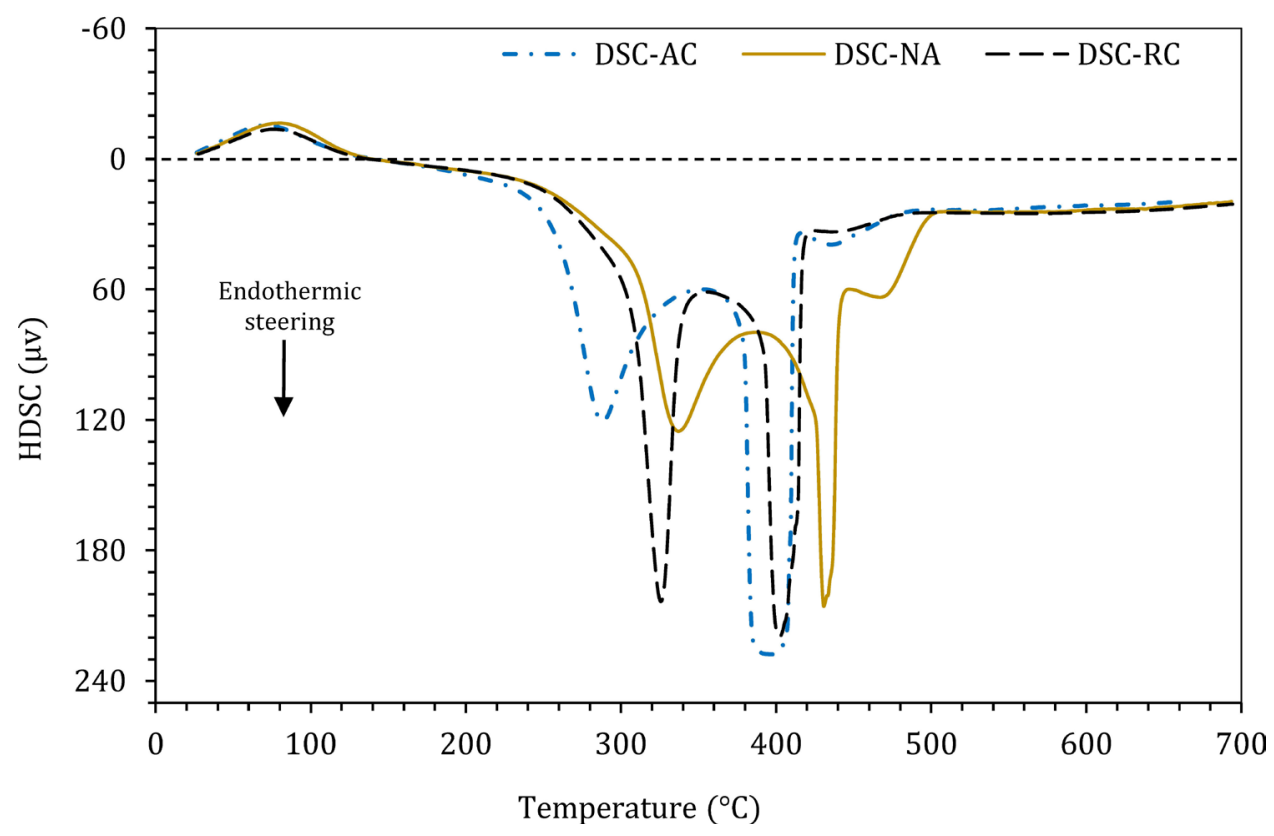

Figure 5. DSC thermogram of AC, NA and RC fibres.

decomposition of $\alpha$-cellulose and lignin [33] [34].

\subsubsection{Thermal Characteristics TGA}

The thermal degradation curves (TG) and their derivatives (DTG) of AC, NA and RC plant fibres measured under nitrogen flow are shown in Figure 6.

The TGA curves show that the fibres under study break down into four phases. This thermal behaviour is typical of plant fibres to that of plant fibres (flax [9], jute [35], sisal [9], kenaf [35], etc.). The first noticeable change starts at $30^{\circ} \mathrm{C}$ and ends at $115^{\circ} \mathrm{C}, 120^{\circ} \mathrm{C}$ and $125^{\circ} \mathrm{C}$ for AC, NA and RC fibres respectively, which is due to the evaporation of their structural moisture and volatile extractives. The mass loss recorded in this phase is the same (about $8.2 \%$ ) for the fibres studied. After dehydration of these fibres, it can be observed that the mass variation is almost constant up to $200^{\circ} \mathrm{C}$ for $\mathrm{AC}, 220^{\circ} \mathrm{C}$ for NA and $285^{\circ} \mathrm{C}$ for RC. The zone of thermal stability thus identified provides details on the maximum service temperature of the fibres under study [36] [37]. The maximum service temperature of AC fibres is very close to that of jute fibres $\left(205^{\circ} \mathrm{C}\right)$, that of NA fibres is similar to that of roselle $\left(200^{\circ} \mathrm{C}\right)$, okra $\left(220^{\circ} \mathrm{C}\right)$ and close to sisal fibres $\left(222^{\circ} \mathrm{C}\right)$ [9], while that of RC fibres is high compared to kenaf fibres $\left(247^{\circ} \mathrm{C}\right)$ [9]. In the second phase, a greater loss of mass was recorded, i.e. $74.41 \%$ between $200^{\circ} \mathrm{C}$ and $475^{\circ} \mathrm{C}$ for $\mathrm{AC}, 63.53 \%$ between $220^{\circ} \mathrm{C}$ and $505^{\circ} \mathrm{C}$ for NA and $71.42 \%$ between $220^{\circ} \mathrm{C}$ and $495^{\circ} \mathrm{C}$ for RC. This loss of mass is attributed to the thermal decomposition of hemicelluloses and pectin between $150^{\circ} \mathrm{C}$ and $250^{\circ} \mathrm{C}$ [9] [38], then that of cellulose between $240^{\circ} \mathrm{C}$ and $350^{\circ} \mathrm{C}$ [33] [38]. The third phase indicates the decomposition of lignin in the studied fibres. A mass loss of $16.27 \%$ was observed for $\mathrm{AC}$ at $495^{\circ} \mathrm{C}, 25.04 \%$ for NA at $505^{\circ} \mathrm{C}$ and $18.11 \%$ for $\mathrm{RC}$ at $495^{\circ} \mathrm{C}$. In the last phase, the mass variation is very small. This constant is 

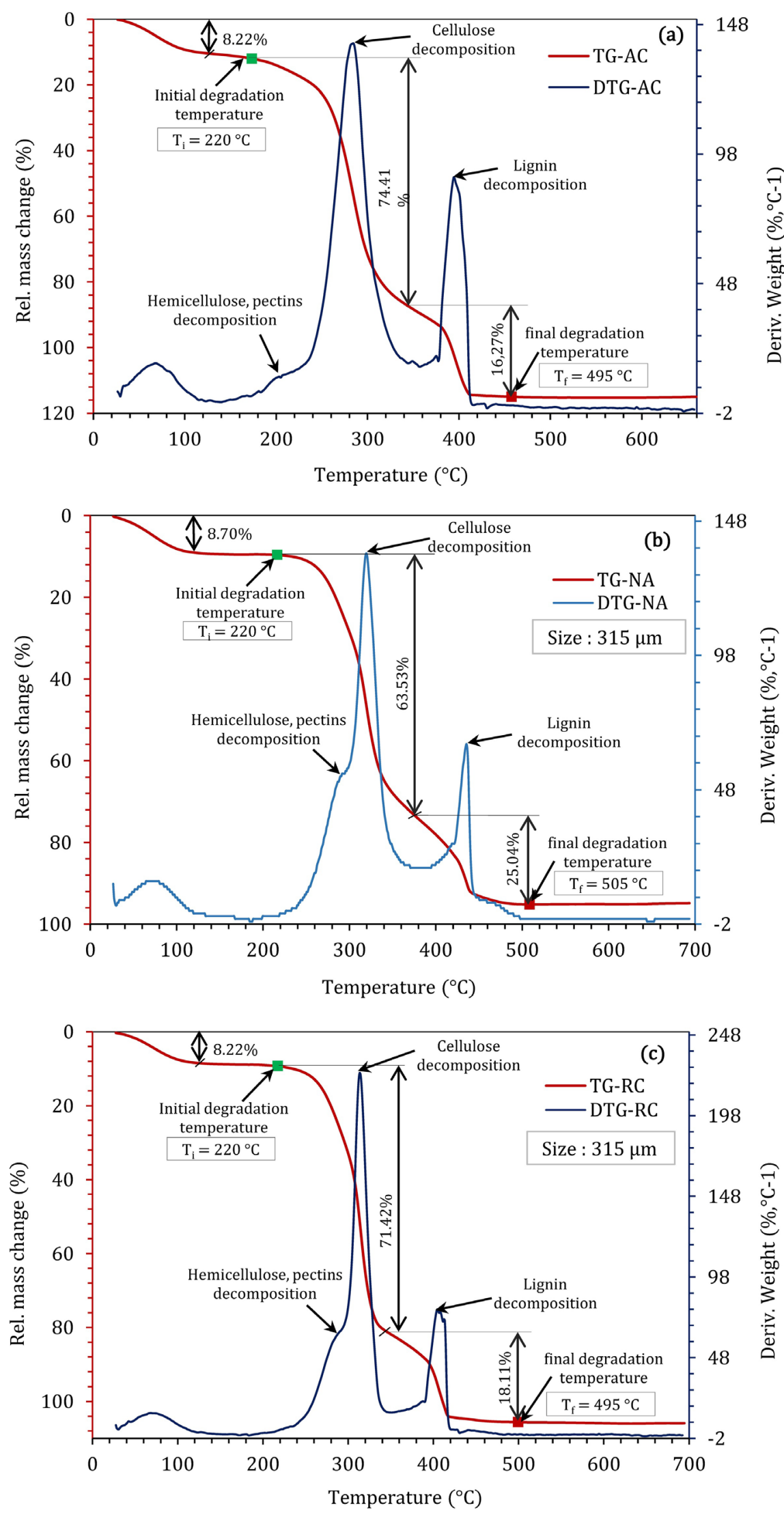

Figure 6. Thermogram TG-DTG of plant fibres: a) AC, b) NA and c) RC. 
due to the formation of ashes. The TGA ash content is $1.12 \%, 2.73 \%$ and $2.25 \%$ respectively for AC, NA and RC fibres.

The TG curves shown in Figure 6, were also used to determine the contents of lignin $(\% L)$, holocellulose $(\% C+\% H)$, ash $(\% C s)$ and volatiles of the studied fibres. The values shown in Table 5 are correlated with the values obtained using the TAPPI method. The content of holocellulose in the fibres of AC and NA is greater than $70 \%$, unlike that of NA.

\section{Conclusion}

This study examined the potential of certain lignocellulosic fibres as biobased fibrous reinforcements for composite materials used in various fields, including internal building thermal insulation. First, the density, water absorption rate and moisture content of AC, NA and RC fibres were evaluated following the recommendations of ASTM D3800-792 and the method of reported by Nadlène et al., respectively. The results obtained showed that the apparent density of RC fibre is lower than that of AC fibre, which is itself lower than that of NA fibre. The NA fibres were more hydrophilic compared to AC and RC fibres. The water absorption rate of AC fibre was low compared to $\mathrm{AC}, \mathrm{RC}$ fibres and some fibres widely studied such as sisal, flax, jute and roselle. The chemical composition of each fibre was obtained using TAPPI methods on fibres reduced to a size of $315 \mu \mathrm{m}$. The content in polysaccharides (cellulose, hemicellulose) of AC and RC fibres which is about $73 \%$ show that these fibres could be interestingly used as reinforcement materials of biosourced materials or as raw materials in the paper industry. On the other hand, the cellulose content (36.08\%) of NA fibres was low. This could give the NA fibres a low tensile strength. However, the high lignin content of this fibre could be extracted and valorized in the production of biofuel. The spectra recorded by ATR-FTIR analysis indicated the functional. According to the FTIR spectra, the cellulose crystallinity index is $67.99 \%, 46.5 \%$ and $59.72 \%$ for AC, NA and RC respectively. Thermal characteristics were studied using DSC and TGA. Thermal degradation of the constituents was observed above $200^{\circ} \mathrm{C}$ for $\mathrm{AC}$ and $220^{\circ} \mathrm{C}$ for NA and RC fibres. Thermal transition phases observed from DSC and TG/DTG thermograms exhibited three major zones related to the degradation of hemicellulose/pectins, cellulose and lignin. These results clarify the temperature domains for the processing and use of fibres and materials reinforced with them. Further studies could focus on the tensile, XRD,

Table 5. Chemical composition deduced on TGA from plant fibres of AC, NA and RC.

\begin{tabular}{ccccc}
\hline & \multicolumn{4}{c}{ Chemical composition (\%) } \\
\cline { 2 - 4 } Fibre & $\% L$ & $\% C+\% H$ & $\% C s$ & Volatiles \\
\cline { 2 - 4 } AC & 16.27 & 74.41 & 1.12 & 8.20 \\
NA & 25.04 & 63.53 & 2.73 & 8.70 \\
RC & 18.11 & 71.42 & 2.25 & 8.22 \\
\hline
\end{tabular}


and SEM characterization of AC, NA, and RC fibres. Investigations could also be done on the characterization of treated fibres, reinforcement of ceramic matrix composites.

\section{Acknowledgements}

The authors are grateful for the technical support provided by Dr. Gustave Kenne for the ATR-FTIR analyses and by Prof. Antoine Elimbi for TGA analyses. The authors are also grateful for the technical support provided by Herman Assonfack for the chemical characterization of the fibres.

\section{Conflicts of Interest}

The authors declare no conflicts of interest regarding the publication of this paper.

\section{References}

[1] Ntenga, R. (2007) Modélisation Multi-échelle et Caractérisation de l'Anisotropie Elastique de Fibres Végétales pour le Renforcement de Matériaux Composites. PhD Thesis, Blaise Pascal Clermont-Ferrand II University/University of Yaoundé I, Yaoundé.

[2] Baley, C. (2004) Fibres Naturelles de Renfort pour Matériaux Composites. Techniques de l’Ingénieur, AM 5130.

[3] Page, J. (2017) Formulation et Caractérisation d'un Composite Cimentaire Biofibré pour des Procédés de Construction Préfabriquée. Ph.D. Thesis, Normandy University, Normandy.

[4] Betene, E.F. (2012) Étude des Propriétés Mécaniques et Thermiques du Plâtre Renforcé de Fibres Végétales Tropicales. Ph.D. Thesis, Blaise Pascal Clermont-Ferrand II University/University of Douala, Douala. https://doi.org/10.13140/RG.2.2.36627.53284

[5] Betene, E.F., Nnengue, E.Y.S., Atangana, A.J., Saha, T.J.B., Tcheumani, Y.A.M. and Tawe, L. (2019) Evaluation of Micromechanical Properties of Neuropeltis acuminatas (NA) Fibers. International Journal of Academic Research and Reflection, 7, 23-36.

[6] Atangana, A., Nnengue, E.S.Y., Betene, E.F., Tawe, L. and Saha, T.J.B. (2019) Morphological and Mechanical Characteristics of Neuropeltis Acuminatas (NA) Fibers. International Journal of Academic Research and Reflection, 7, 22-31.

[7] Asim, M., Abdan, K., Jawaid, M., Nasir, M., Dashtizadeh, Z., Ishak, M.R. and Hoque, M.E. (2015) A Review on Pineapple Leaves Fibre and Its Composites. International Journal of Polymer Science, 2015, Article ID: 950567. https://doi.org/10.1155/2015/950567

[8] Dumont, P.J.J., Orgéas, L., Martoïa, F., Budtova, T. and Vincent, M. (2017) Article Title. In: Berzin, F., Ed., Composites polymères et fibres lignocellulosiques, Propriétés, transformation et caractérisation, Chapter 5, Lavoisier Hermes, City, 160-201.

[9] Nadlene, R., Sapuan, S.M., Jawaid, M., Ishak, M.R. and Yusriah, L. (2015) Material Characterization of Roselle Fibre (Hibiscus sabdariffa L.) as Potential Reinforcement Material for Polymer Composites. Fibres and Textiles in Eastern Europe, 6, 23-30. https://doi.org/10.5604/12303666.1167413

[10] Baley, C., Le Duigou, A., Bourmaud, A. and Davies, P. (2012) Influence of Drying on the Mechanical Behaviour of Flax Fibres and Their Unidirectional Composites. 
Composites Part A: Applied Science and Manufacturing, 43, 1226-1233. https://doi.org/10.1016/j.compositesa.2012.03.005

[11] Youmssi, D.V.C., Bampel, Y.D.M., Njankouo, J.M., Saha, J.-B. and Ndikontar, M.K. (2017) Chemical Composition of Some Plantation Wood Species (Eucalyptus saligna, Cupressus lusitanica and Eucalyptus paniculata) and Assessment of Compatibility with Plaster. Journal Indian Academy of Wood Science, 14, 146-153. https://doi.org/10.1007/s13196-017-0200-3

[12] Sango, T., Yona, A.M.C., Duchatel, L., Marin, A., Ndikontar, M., Joly, N. and Lefebvre, J.M. (2018) Step-Wise Multi-Scale Deconstruction of Banana Pseudo-Stem (Musa acuminata) Biomass and Morpho-Mechanical Characterization of Extracted Long Fibres for Sustainable Applications. Industrial Crops and Products, 122, 657-668. https://doi.org/10.1016/j.indcrop.2018.06.050

[13] Parida, C., Dash, S.K. and Pradhan, C. (2015) FTIR and Raman Studies of Cellulose Fibers of Luffa cylindrica. Open Journal of Composite Materials, 5, 5-10. https://doi.org/10.4236/ojcm.2015.51002

[14] Béakou, A., Ntenga, R., Lepetit, J., Atéba, J.A. and Ayina, L.O. (2008) Physico-Chemical and Microstructural Characterization of "Rhectophyllum camerunense" Plant Fiber. Composites Part A: Applied Science and Manufacturing, 39, 67-74. https://doi.org/10.1016/j.compositesa.2007.09.002

[15] Uddin, N., Miah, S., Abdul, M., Jalil, M.A., Islam, M. and Ayesha, S. (2017) A Review on Extraction, Characterization and Application of Pineapple Leaf Fiber (PALF) in Textiles and Other Fields. International Journal of Advanced Research, 5 , 112-116. https://doi.org/10.21474/IJAR01/3786

[16] Aizi, D.E. (2017) Extraction, Caractérisation Morphologique, Physico-chimique et Mécanique des Fibres Caulinaires de Retama monosperma L. Boiss. PhD Thesis, Oran Mohamed Boudiaf University of Science and Technology, Algeria.

[17] Faruk, O., Bledzki, A.K., Fink, H.-P. and Sain, M. (2012) Biocomposites Reinforced with Natural Fibers: 2000-2010. Progress in Polymer Science, 37, 1552-1596. https://doi.org/10.1016/j.progpolymsci.2012.04.003

[18] Roudier, A., Charlet, K., Moreno, F., Toussaint, E., Géneau-Sbartaï, C., Commereuc, S., Verney, V. and Béakou, A. (2010) Caractérisation des Propriétés Biochimiques et Hygroscopiques d'une Fibre de Lin. Matériaux \& Techniques, 100, 525-535. https://doi.org/10.1051/mattech/2012044

[19] Noutegomo, B., Betene, E. and Atangana, A. (2019) Study of the Diffusion Behavior of Water Vapor Sorption in Natural Fiber Composite: Plaster/Rhecktophyllum Camerunense. MOJ Applied Bionics and Biomechanics, 3, 1. https://doi.org/10.15406/mojabb.2019.03.00093

[20] Elenga, R.G., Dirras, G.F., Goma, M.J., Djema, P. and Biget, M.P. (2009) On the Picrostructure and Physical Properties of Untreated Raffia textilis Fiber. Composites. Part A: Applied Science and Manufacturing, 40, 418-422. https://doi.org/10.1016/j.compositesa.2009.01.001

[21] Hachmi, M. and Moslemi, A.A. (1989) Correlation between Wood-Cement Compatibility and Wood Extractives. Forest Products Journal, 39, 55-58.

[22] Taallah, B., Guettala, A. and Kriker, A. (2014) Effet de la Teneur en Fibres de Palmier Dattier et de la Contrainte de Compactage sur les Propriétés des Blocs de Terre Comprimée. Materials Science, Courrier du Savoir, 18, 45-51.

[23] Cotugno, S., Larobina, D., Mensitieri, G., Musto, P. and Ragosta, G. (2001) A Novel Spectroscopic Approach to Investigate Transport Processes in Polymers: The Case of Water-Epoxy System. Polymer, 42, 6431-6438. 
https://doi.org/10.1016/S0032-3861(01)00096-9

[24] Mouhoubi, S., Osmani, H., Bali, T. and Abdeslam, S. (2012) Élaboration et Étude des Propriétés des Composites Polyester/alfa Traitée et Non Traitée. Verres, Céramiques \& Composites, 2, 34-40.

[25] Saad, H. (2013) Développement de Bio-composites à Base de Fibres Végétales et de Colles Écologiques. PhD Thesis, University of Pau et des Pays de l'Adour, Pau.

[26] Bilba, K., Arsene, M.-A. and Ouensanga, A. (2007) Study of Banana and Coconut Fibers Botanical Composition, Thermal Degradation and Textural Observations. Bioresource Technology, 98, 58-68. https://doi.org/10.1016/j.biortech.2005.11.030

[27] Bellamy, L.J. (1975) The Infra-Red Spectra of Complex Molecules. Chapman and Hall, London, 111-112. https://doi.org/10.1007/978-94-011-6017-9

[28] Ouajai, S. and Shanks, R.A. (2005) Composition, Structure and Thermal Degradation of Hemp Cellulose after Chemical Treatments. Polymer Degradation and Stability, 89, 327-335. https://doi.org/10.1016/j.polymdegradstab.2005.01.016

[29] De Rosa, I.M., Kenny, J.M., Puglia, D., Santulli, C. and Sarasini, F. (2010) Morphological, Thermal and Mechanical Characterization of Okra (Abelmoschus esculentus) Fibres as Potential Reinforcement in Polymer Composites. Composites Science and Technology, 70, 116-122. https://doi.org/10.1016/j.compscitech.2009.09.013

[30] Fengel, D. (1992) Characterization of Cellulose by Deconvoluting the $\mathrm{OH}$ Valency Range in FTIR Spectra. Holzforschung, 46, 283-288. https://doi.org/10.1515/hfsg.1992.46.4.283

[31] Kondo, T. (1997) The Assignment of IR Absorption Bands Due to Free Hydroxyl Groups in Cellulose. Cellulose, 4, 281-292. https://doi.org/10.1023/A:1018448109214

[32] Dai, D. and Fan, M. (2011) Investigation of the Dislocation of Natural Fibres by Fourier-Transform Infrared Spectroscopy. Vibrational Spectroscopy, 55, 300-306. https://doi.org/10.1016/j.vibspec.2010.12.009

[33] Milani, M.D.Y., Samarawickrama, D.S., Dharmasiri, G.P.C.A. and Kottegoda, I.R.M. (2016) Study the Structure, Morphology, and Thermal Behavior of Banana Fiber and Its Charcoal Derivative from Selected Banana Varieties. Journal of Natural Fibers, 13, 332-342. https://doi.org/10.1080/15440478.2015.1029195

[34] Ntenga, R., Mfoumou, E., Béakou, A., Tango, M., Kamga, J. and Ahmed, A. (2018) Insight on the Ultrastructure, Physicochemical, Thermal Characteristics and Applications of Palm Kernel Shells. Materials Sciences and Applications, 9, 790-811. https://doi.org/10.4236/msa.2018.910057

[35] Deepa, B.E., Abraham, B.M., Cherian, A., Bismarck, J.J., Blaker, L.A., Pothan, A.L., Leao, S.F.D., Souza and Kottaisamy, V. (2011) Structure, Morphology and Thermal Characteristics of Banana Nano Fibers Obtained by Steam Explosion. Bioresource Technology, 102, 1988-1997. https://doi.org/10.1016/j.biortech.2010.09.030

[36] Ornaghi Júnior, H.L., Zattera, A.J. and Amico, S.C. (2013) Thermal Behavior and the Compensation Effect of Vegetal Fibers. Cellulose, 21, 189-201.

https://doi.org/10.1007/s10570-013-0126-x

[37] Teixeira, F.P., Otávio da, F.M.G. and Flávio, A.S. (2019) Degradation Mechanisms of Curaua, Hemp, and Sisal Fibers Exposed to Elevated Temperatures. Thermal Degradation of Fibers, Bioresources, 14, 1494-1511.

[38] Tanobe, V.O.A., Sydenstricker, T.H.D., Munaro, M. and Amico, S.C. (2005) A Comprehensive Characterization of Chemically Treated Brazilian Sponge-Gourds (Luffa cylindrica). Polymer Testing, 24, 474-482. https://doi.org/10.1016/j.polymertesting.2004.12.004 